\title{
Article \\ Characterization of Heat-Polymerized Monomer Formulations for Dental Infiltrated Ceramic Networks
}

\author{
Janine Tiu, Renan Belli and Ulrich Lohbauer *(D) \\ Research Laboratory for Dental Biomaterials, Dental Clinic 1-Operative Dentistry and Periodontology, \\ University of Erlangen-Nuremberg, Glueckstrasse 11, 91054 Erlangen, Germany; janine.tiu@gmail.com (J.T.); \\ renan.belli@fau.de (R.B.) \\ * Correspondence: ulrich.lohbauer@fau.de; Tel.: +49-9131-8543-740; Fax: +49-9131-8534-207
}

Citation: Tiu, J.; Belli, R.; Lohbauer, U. Characterization of Heat-Polymerized Monomer Formulations for Dental Infiltrated Ceramic Networks. Appl. Sci. 2021, 11, 7370. https://doi.org/ 10.3390/app11167370

Academic Editor: Mitsuru Motoyoshi

Received: 16 July 2021

Accepted: 9 August 2021

Published: 11 August 2021

Publisher's Note: MDPI stays neutral with regard to jurisdictional claims in published maps and institutional affiliations.

Copyright: (c) 2021 by the authors. Licensee MDPI, Basel, Switzerland. This article is an open access article distributed under the terms and conditions of the Creative Commons Attribution (CC BY) license (https:// creativecommons.org/licenses/by/ $4.0 /)$.

\begin{abstract}
Objectives: This work examined properties of dental monomer formulations of an aromatic dimethacylate (BisGMA), aliphatic urethane dimethacrylate (UDMA), and triethylene glycol dimethacrylate (TEGDMA). The monomers were combined in different ratio formulations and heat-polymerized containing the initiator benzoyl peroxide (BPO) specifically for the purpose of infiltration into polymer-infiltrated composite structures. (2) Methods: The monomers were combined in different weight ratios and underwent rheological analysis (viscosity and temperature dependence), degree of conversion, and mechanical properties (elastic modulus, hardness, fracture toughness). (3) Results: Rheological properties showed Newtonian behavior for monomers with a large dependence on temperature. The addition of BPO allowed for gelation in the range of $72.0-75.9^{\circ} \mathrm{C}$. Degree of conversion was found between $74 \%$ and $87 \%$ DC, unaffected by an increase of TEGDMA (up to $70 \mathrm{wt} \%$ ). Elastic modulus, hardness, and fracture toughness were inversely proportional to an increase in TEGDMA. Elastic modulus and hardness were found slightly increased for UDMA versus BisGMA formulations, while fracture toughness ranged between 0.26 and $0.93 \mathrm{MPa} \cdot \mathrm{m}^{0.5}$ for UDMAand 0.18 and $0.68 \mathrm{MPa} \cdot \mathrm{m}^{0.5}$ for BisGMA-based formulations. (4) Significance: Heat-polymerization allows for greater range of monomer formulations based on viscosity and degree of conversion when selecting for infiltrated composite structures. Therefore, selection should be based on mechanical properties. The measured data for fracture toughness combined with the reduced viscosity at higher UDMA:TEGDMA ratios favor such formulations over BisGMA:TEGDMA mixtures.
\end{abstract}

Keywords: methacrylate monomer; heat polymerization; mechanical properties; resin infiltration

\section{Introduction}

Resin composites are successful and versatile in dental restorative applications. The assembled constituents of organic polymers, inorganic fillers, and silane coupling agent $[1,2]$ result in an expansive array of mechanical and structural properties. By developing towards biomimetic design in dental materials, the expanded use of dental monomers comes into focus. In particular, several groups have challenged convention and moved towards composites with continuous and interconnected rigid and pliable constituents [3-17]. Additionally, known as polymer infiltrated ceramic networks (PICN), these materials must be preprocessed as CAD/CAM (computer aided design/computer aided manufacturing) blocks or discs. The conditions for infiltration through a rigid porous structure differ from the mixing of conventional particle reinforced structures $[18,19]$. The infiltration process can be represented by Darcy's Law, which describes fluid flow through a porous medium [20]. Besides geometry, the determining factors are the pressure gradient, the permeability of the porous medium, and the viscous behavior of the fluid. In the case of PICN composites, the pressure gradient is determined by the vacuum pressure exerted in impregnation machines, the permeability is determined from the geometry of porosity (i.e., size of ceramic particles and partial sintering conditions), and the viscosity is of the monomer. 
The conventional dental base monomers in composite formulations include Bisphenol A diglycidyl ether dimethacrylate (BisGMA), urethane dimethacrylate (UDMA), and triethyleneglycol dimethacrylate (TEGDMA) [21], the last of which is used as a diluent and therefore dictates viscosity based on ratio formulations. The chemical structures of the monomers are shown in Figure 1.<smiles>CC(C)C(=O)OCC(O)COc1ccc(C(C)(C)c2ccc(OCC(O)COC(=O)C(C)C)cc2)cc1</smiles>

BisGMA<smiles>C=C(C)C(=O)OCCOC(=O)NCCC(C)CC(C)(C)C[C@H](C)OCCOC(=O)C(C)C</smiles><smiles></smiles>

Figure 1. Molecular structure of dental monomers.

BisGMA is advantageous in that it has a high molecular weight and presents lower polymerization shrinkage. The stiff Bisphenol A core and two pendant hydroxyl groups allow for strong hydrogen bonds to be formed and have the largest and lowest concentration of double bonds [22]. On the other hand, UDMA has a flexible aliphatic core with two urethane links [23]. It is smaller than BisGMA and has a higher concentration of double bonds. TEGDMA is the smallest in size, has a high concentration of double bonds, but in turn has the greatest shrinkage. These three monomers in differing formulations comprise the majority of resin matrices used in dental composites.

For photo-polymerized resins under ambient temperatures, the double bond conversion is rapid [24]. As the resin turns glassy and vitrifies, mobility is reduced, continued monomer conversion is hindered, and reaction rate slows [25,26]. Mobility is greatly reduced to the extent that photo-polymerization will always lead to incomplete conversion. Photo-polymerized composites are guided by principles to maximize the degree of conversion as insufficient conversion could lead to color instability and material degradation [27-31]. Conversely, heat polymerization as used by PICN materials allows the consistent input requirements of heat energy to continue the reaction which results in a higher degree of conversion. Numerous studies have reported on mechanical property characterizations of photo-polymerized unfilled dental resins, including degree of conversion [32-34], elastic modulus [35], hardness [34,36,37], and fracture toughness [38]. In comparison, few studies report on mechanical properties of heat-polymerized unfilled dental resins. Nguyen [39] and colleagues found significant differences in strength between photo-polymerized and heat-polymerized UDMA, with significant increases with increased temperature and pressure. It is unclear how monomer formulations and differences in heat-polymerization protocols affect mechanical properties.

To establish a starting baseline, relevant research groups producing experimental dental PICN materials are summarized in Table 1. Here, information on the monomer formulations, the initiator type, and the polymerization protocol are extracted and presented as given. Common formulations are UDMA:TEGDMA and BisGMA:TEGDMA, both in a 1:1 weight ratio, and the most common initiator is $1 \mathrm{wt} \%$ Benzoyl Peroxide (BPO). Furthermore, heating protocols vary between groups. The minimum temperature for formulations with the heat initiator $\mathrm{BPO}$ is $70^{\circ} \mathrm{C}$ increasing up to $110^{\circ} \mathrm{C}$, the holding time also differs from $2 \mathrm{~h}$ to $24 \mathrm{~h}$, and some groups polymerize under high pressure. While 
it is possible that the choices made using heat-polymerization procedures are optimal, there has been no indication as to whether these monomer formulations are ideal and how they contribute to the mechanical properties of the PICN. Indeed, with experimental composites, characterizing base constituents must be pursued if the ideal PICN composite is to be constructed.

Table 1. Literature review on relevant monomer formulations for resin infiltration of porous ceramic networks.

\begin{tabular}{|c|c|c|c|c|c|c|}
\hline Reference & Year & Rigid Network & Monomer/s & Initiator & $\begin{array}{l}\text { Polymerization } \\
\text { Protocol }\end{array}$ & $\begin{array}{l}\text { Pressure (If } \\
\text { Applicable) }\end{array}$ \\
\hline Coldea et al. [4] & 2013 & Feldspar & UDMA:TEGDMA & $\mathrm{BPO}$ & & \\
\hline Petrini et al. [14] & 2013 & Alumina & Epoxy & & $40^{\circ} \mathrm{C} 24 \mathrm{~h}$ & \\
\hline Steier et al. [15] & 2013 & Alumina & UDMA:TEGDMA 1:1 & $0.3 \mathrm{vol} \% \mathrm{BPO}$ & $100^{\circ} \mathrm{C} 2 \mathrm{~h}$ & $280 \mathrm{MPa}$ \\
\hline Li et al. [12] & 2013 & $\mathrm{ZrO} 2$ & MMA & BPO & & \\
\hline Li et al. [11] & 2014 & Yzr & PMMA & $\mathrm{BPO}$ & $85^{\circ} \mathrm{C}, 20 \mathrm{~h}$ & \\
\hline Nguyen et al. [13] & 2014 & Albite glass & UDMA & $\begin{array}{l}0.5 \mathrm{wt} \% \text { di-tert-amyl } \\
\text { peroxide }\end{array}$ & $180^{\circ} \mathrm{C}$ & $300 \mathrm{MPa}$ \\
\hline Cui et al. [7] & 2016 & $\begin{array}{l}\text { Feldspar (potassium, } \\
\text { sodium, calcium) }\end{array}$ & BisGMA:TEGDMA 1:1 & $\mathrm{BPO}$ & $\begin{array}{l}70^{\circ} \mathrm{C} 8 \mathrm{~h}, \\
110^{\circ} \mathrm{C} 8 \mathrm{~h}\end{array}$ & \\
\hline Wang et al. [17] & 2017 & $\begin{array}{l}\text { Sodium aluminium } \\
\text { silicate }\end{array}$ & BisGMA:TEGDMA 1:1 & $1 \mathrm{wt} \% \mathrm{BPO}$ & $70^{\circ} \mathrm{C} 16 \mathrm{~h}$ & \\
\hline $\begin{array}{l}\mathrm{Li} \text { and Sun [40] } \\
\mathrm{Li} \text { et al. [10] }\end{array}$ & $\begin{array}{l}2017 \\
2017\end{array}$ & $\begin{array}{l}\text { Zirconia } \\
\text { 3Y-TZP }\end{array}$ & $\begin{array}{c}\text { UDMA:TEGDMA 1:1 } \\
\text { BisGMA:TEGDMA 1:1 }\end{array}$ & $\mathrm{BPO}$ & $\begin{array}{c}180^{\circ} \mathrm{C} \\
70^{\circ} \mathrm{C} 10 \mathrm{~h}\end{array}$ & $300 \mathrm{MPa}$ \\
\hline Cui et al. [5] & 2017 & $\begin{array}{l}\text { Sodium aluminium } \\
\text { silicate }\end{array}$ & BisGMA:TEGDMA 1:1 & $1 \mathrm{wt} \% \mathrm{BPO}$ & $\begin{array}{l}70^{\circ} \mathrm{C} 8 \mathrm{~h} \\
110^{\circ} \mathrm{C} 8 \mathrm{~h}\end{array}$ & \\
\hline Eldafrawy et al. [9] & 2018 & Albite glass & UDMA & $\begin{array}{l}0.5 \mathrm{wt} \% \text { di-tert-amyl } \\
\text { peroxide }\end{array}$ & $180^{\circ} \mathrm{C}$ & $300 \mathrm{MPa}$ \\
\hline Al-Jawoosh et al. [3] & 2018 & Alumina & UDMA:TEGDMA 1:1 & $1 \mathrm{vol} \% \mathrm{BPO}$ & $\begin{array}{c}50^{\circ} \mathrm{C} 2 \mathrm{~h}, 60^{\circ} \mathrm{C} \\
3 \mathrm{~h}, 70^{\circ} \mathrm{C} 6 \mathrm{~h}, \\
90^{\circ} \mathrm{C} 12 \mathrm{~h}\end{array}$ & \\
\hline Cui et al. [8] & 2019 & $\begin{array}{l}\text { Potassium } \\
\text { aluminosilicate }\end{array}$ & BisGMA:TEGDMA 1:1 & $1 \mathrm{wt} \% \mathrm{BPO}$ & $\begin{array}{c}70{ }^{\circ} \mathrm{C} 8 \mathrm{~h}, 110 \\
{ }^{\circ} \mathrm{C} 8 \mathrm{~h}\end{array}$ & \\
\hline Wang et al. [16] & 2019 & Silicon nitride & MMA & $1 \mathrm{wt} \% \mathrm{BPO}$ & & \\
\hline Cui et al. [6] & 2020 & $\begin{array}{l}\text { Sodium aluminium } \\
\text { silicate } \\
\text { nanohydroxyapatitie }\end{array}$ & BisGMA:TEGDMA 1:1 & $1 \mathrm{wt} \% \mathrm{BPO}$ & $\begin{array}{l}70{ }^{\circ} \mathrm{C} 8 \mathrm{~h}, 110 \\
{ }^{\circ} \mathrm{C} 8 \mathrm{~h}\end{array}$ & \\
\hline
\end{tabular}

PICN composites attempt to combine favorable properties of two rather contrasting materials [18]. While the rigid constituent of PICN composites can be almost any type of dental grade ceramic, from porcelain $[7,13,17]$ to high strength alumina $[3,14,15]$ and zirconia [10-12], the monomer constituent is more limiting. A wide range of mechanical performances results from any number of rigid and pliable material combinations. Without a foundational understanding of the monomer constituent, development of experimental heatpolymerized dental composites is limited. The focus of this study was to elucidate specific properties of the heat-polymerized monomer matrix, especially significant in experimental material design. Although the mechanical properties of the PICN may well differ from its constituent materials, optimized properties and efficient composite design culminate from our understanding of the basic constituents. This is not an exhaustive report but a continued contribution in monomer formulation selection. Rheological analysis, degree of conversion, and selected mechanical properties measurements were employed. Therefore, the aim of this study is the characterization of heat-polymerized dental monomer formulations.

\section{Experimental}

\subsection{Materials}

The dental monomers BisGMA, UDMA, and TEGDMA and heat-initiator benzoyl peroxide (BPO) were used as provided by a dental manufacturer (VOCO, Germany). While volume percentage or mole fraction would be chemical convention, the study refers to them in weight percentage as this is the measure given in all experimental PICN studies. $\mathrm{BPO}$ was kept constant at $1 \mathrm{wt} \%$. Different weight ratio mixtures of BisGMA:TEGDMA were 9:1 (89.43 vol $\%: 10.57 \mathrm{vol} \%)$, 8:2 (79.00 vol $\%: 21.00 \mathrm{vol} \%), 7: 3$ ( $68.70 \mathrm{vol} \%: 31.30 \mathrm{vol} \%)$, 6:4 (58.5 vol\%:41.48 vol\%), 5:5 (48.47 vol\%:51.53 vol \%), 4:6 (38.54 vol\%:61.46 vol\%), 3:7 
(28.73 vol\%:71.27 vol\%), 2:8 (19.04 vol\%:80.96 vol\%), and 1:9 (9.46 vol\%:90.54 vol\%). Weight ratios mixtures of UDMA:TEGDMA were 9:1 (89.85 vol\%:10.15 vol\%), 8:2 (79.74 vol\%:20.26 vol\%), 7:3 (69.66 vol\%:30.34 vol\%), 6:4 (59.61 vol\%:40.39 vol\%), 5:5 (49.59 vol\%:50.41 vol\%), $4: 6$ (39.61 vol\%:60.39 vol\%), 3:7 (29.66 vol\%:70.34 vol\%), 2:8 (19.74 vol\%:80.26 vol\%), and 1:9 (9.85 vol\%:90.15 vol\%).

\subsection{Viscosity}

Monomer mixtures were weighed and measured into small plastic containers (4 g) and premixed by hand with a small bamboo stick. Containers were placed into a dual asymmetric centrifuge (SpeedMixer ${ }^{\mathrm{TM}}$ DAC 150 SP, Hauschild, Germany) at $3000 \mathrm{rpm}$ until the mixtures were consistent (up to $4 \mathrm{~min}$ ). Mixtures were stored at $40{ }^{\circ} \mathrm{C}$ for at least $24 \mathrm{~h}$. Viscosity measurements were performed using a rheometer (MCR 301, Anton Paar, Austria) with a $25 \mathrm{~mm}$ parallel aluminum disk and plate geometry with gap size between 0.3 and $0.5 \mathrm{~mm}$. Rotational shear sweep test was performed at $25^{\circ} \mathrm{C}$ with shear rates of $0.001-100(1 / \mathrm{s})$. Forty points were recorded, each test was repeated 3 times, and means were calculated. Rotational temperature sweep tests were performed on monomer mixes with viscosity $>0.01 \mathrm{~Pa} \cdot \mathrm{s}\left(25^{\circ} \mathrm{C}\right)$. Temperature was increased from $20{ }^{\circ} \mathrm{C}$ to $45{ }^{\circ} \mathrm{C}$ at $1^{\circ} \mathrm{C} / \mathrm{min}$ with a constant shear rate of $101 / \mathrm{s}$. Twenty-five data points were collected and plotted with complex viscosity $\left(\eta^{*}\right)$. Data were analyzed using statistical software (SPSS ver, IBM Corp, Armonk, NY, USA) at $p<0.05$ significance level. One-way ANOVA was used to compare the viscosity at each temperature $\left(20^{\circ} \mathrm{C}\right.$ and $\left.45^{\circ} \mathrm{C}\right)$.

\subsection{Temperature-Dependent Behavior}

Mixing and resting protocol was the same for viscosity with the initial step of TEGDMA mixed together with $1.0 \mathrm{wt} \%$ BPO until dissolved, before BisGMA or UDMA were added according to the monomer mixes. Temperature-dependent behavior was performed on the mixtures (UDMA:TEGDMA, 2:8, 5:5, 8:2; BisGMA:TEGDMA, 2:8, 5:5, 8:2) using a rheometer (MCR 301, Anton Paar, Austria) with a $15 \mathrm{~mm}$ parallel aluminium disk and plate geometry with gap size $0.5 \mathrm{~mm}$. Oscillatory tests with angular frequency of $10 \mathrm{rad} / \mathrm{s}$, amplitude of $5 \%$, and temperature rate of $1{ }^{\circ} \mathrm{C} / \mathrm{min}$ were performed with temperatures starting from $24{ }^{\circ} \mathrm{C}$ to $90^{\circ} \mathrm{C}$. Storage modulus $\left(\mathrm{G}^{\prime}\right)$ and loss modulus $\left(\mathrm{G}^{\prime \prime}\right)$ were plotted, and the sol/gel transition $\left(\mathrm{T}_{\mathrm{sg}}\right)$ temperature (phase transition when $\mathrm{G}^{\prime}=\mathrm{G}^{\prime \prime}$, equivalent to loss factor $\delta$ ) was the point determining when the monomer became solid/polymerized.

\subsection{Mechanical Properties}

Mixing and resting protocol was the same for temperature-dependent behavior tests. Monomer mixtures were placed into custom silicon molds and allowed to sit overnight before the heating protocol. Specimens were heated from room temperature to $60{ }^{\circ} \mathrm{C}$ for $1 \mathrm{~h}\left(5^{\circ} \mathrm{C} / \mathrm{min}\right)$, raised until the final temperature $\left(80^{\circ} \mathrm{C}, 100{ }^{\circ} \mathrm{C}\right.$, and $\left.120^{\circ} \mathrm{C}\right)$, and held for $8 \mathrm{~h}$. An $8 \mathrm{~h}$ maximum was chosen according to the limitations of the laboratory working hours. The oven was switched off and specimens were allowed to slow cool overnight. Polymers were cut into bar specimens $(25 \mathrm{~mm} \times 5 \mathrm{~mm} \times 2.5 \mathrm{~mm})$ using a precision sectioning saw (IsoMet ${ }^{\mathrm{TM}}$ Low Speed Saw, Buehler, Plymouth, MN, USA) and polished (up to 4000 grit). Fracture toughness specimens requiring a precrack $(a)$ were created using a $1 \mathrm{~mm}$ thick diamond disk to length $0.5 \mathrm{~mm}$ using a custom notching machine. A razor blade was inserted into the shallow cut and a short tap created a notch with a sharp tip into the specimen. Precrack length was measured using an optical stereomicroscope (SteREO Discovery.V8, Zeiss, Oberkochen, Germany) with camera (AxioCam, Zeiss, Germany) and measuring software (Zen Core 2.7, Zeiss, Germany).

Specimens were tested in a universal testing machine (Z2.5, Zwick/Roell, Ulm, Germany) in a 3-point bending set-up (3-PB), with span (S) $20 \mathrm{~mm}$, and crosshead speed of $0.01 \mathrm{~mm} / \mathrm{min}$. Specimens without notches were used for Young's modulus $(n=6)$, and pre-cracked specimens were used for fracture toughness $(n=6)$. Displacement was captured using an attached laser extensometer (laserXtens, Zwick/Roell, Germany) and 
recorded on software (testXpert III, Zwick/Roell, Germany). Mean and corresponding standard deviations as a measure of variability were calculated for each group.

Fracture toughness $\left(K_{\mathrm{IC}}\right)$ calculated according to ASTM E1820 given by the equation

$$
K_{\mathrm{IC}}=\left[\frac{P S}{B W^{3 / 2}}\right] f\left(\frac{a}{W}\right)
$$

where $P$ is the load, $B$ is the width of the specimen, $W$ is the height of the specimen, and $f\left(\frac{a}{W}\right)$ for 3-PB is given by

$$
f\left(\frac{a}{W}\right)=\frac{3\left(\frac{a}{W}\right)^{1 / 2}\left[1.99-\left(\frac{a}{W}\right)\left(1-\frac{a}{W}\right)\left(2.15-3.93 \frac{a}{W}+2.7\left(\frac{a}{W}\right)^{2}\right)\right]}{2\left(1+2 \frac{a}{W}\right)\left(1-\frac{a}{W}\right)^{3 / 2}}
$$

Hardness was measured using the Vickers hardness test using the standard DIN EN ISO 6507-1 and VDI/VDE 2626 part 2 as a guide. A diamond indenter with the applied force of $500 \mathrm{~g}$ was held for $30 \mathrm{~s}$ in an analogue materials testing machine (ZHV10, Zwick, Ulm, Germany). Three indentation points per specimen $(n=3, \mathrm{~A}=$ surface area of an indent measured from the diagonal dimensions d) were measured using an upright confocal microscope (Leica DMRXE, Leica Microsystems, Wetzlar, Germany), with an attached camera (AxioCam, Zeiss, Germany) and measuring software (Zen 2, Zeiss, Germany). The hardness value was calculated using the following equation:

$$
H V=\frac{P}{A}=\frac{1.8544 F}{d^{2}}
$$

\subsection{Monomer Conversion}

Monomer conversion was measured using Fourier transform infrared spectrometry (FTIR). Spectra was collected in absorbance with 42 scans at resolution $4 \mathrm{~cm}^{-1}$ over a wavenumber range of $400-4000 \mathrm{~cm}^{-1}$ using an FTIR spectrometer (IRAffinity-1S, Shimadzu, Duisburg, Germany) in conjunction with an ATR (attenuated total reflection) sampling algorithm. Degree of conversion (\%DC) was determined by measuring the remaining proportlion peak intensity of the aliphatic $\mathrm{C}=\mathrm{C}$ double bonds (at absorption band $1638 \mathrm{~cm}^{-1}$ ) in the polymerized specimen relative to the total $\mathrm{C}=\mathrm{C}$ double bonds in the monomer mixture. Unaffected by the polymerization reaction, aromatic C . . C absorption at $1609 \mathrm{~cm}^{-1}$ was used as an internal standard for BisGMA mixtures, while N ... H peak at $1537 \mathrm{~cm}^{-1}$ was used as the internal standard for UDMA [41]. Baseline was determined by connecting points taken in the depressions adjacent to each peak, and intensity was measured by maximum peak height relative to the baseline. \%DC is given by the following equation:

$$
\% \mathrm{DC}=\left[1-\frac{\left(\frac{1638 \mathrm{~cm}^{-1} \text { or } 1537 \mathrm{~cm}^{-1}}{1609 \mathrm{~cm}^{-1}}\right) \text { polymer }}{\left(\frac{1638 \mathrm{~cm}^{-1} \text { or } 1537 \mathrm{~cm}^{-1}}{1609 \mathrm{~cm}^{-1}}\right) \text { monomer }}\right] \times 100
$$

\section{Results and Discussion}

\subsection{Viscosity}

Viscosity is the material property describing the resistance to flow, which is affected by intermolecular interactions. Figure 2 shows the average viscosity of each monomer formulation from a rotational shear sweep test. As the shear stress rate had no effect on viscosity, all formulations showed Newtonian rheological behavior. BisGMA showed the greatest viscosity at $520 \mathrm{~Pa} \cdot \mathrm{s}$ at $25{ }^{\circ} \mathrm{C}$, attributed to its high molecular weight and the strong hydrogen bonding from its two pendant hydroxyl groups [42,43]. The viscosity of TEGDMA, attributed to its low molecular weight [44], is relatively low (0.0084 Pa.s), 
which naturally decreases the viscosity of the monomer formulations as percentage weight increases in accordance with other studies $[45,46]$.
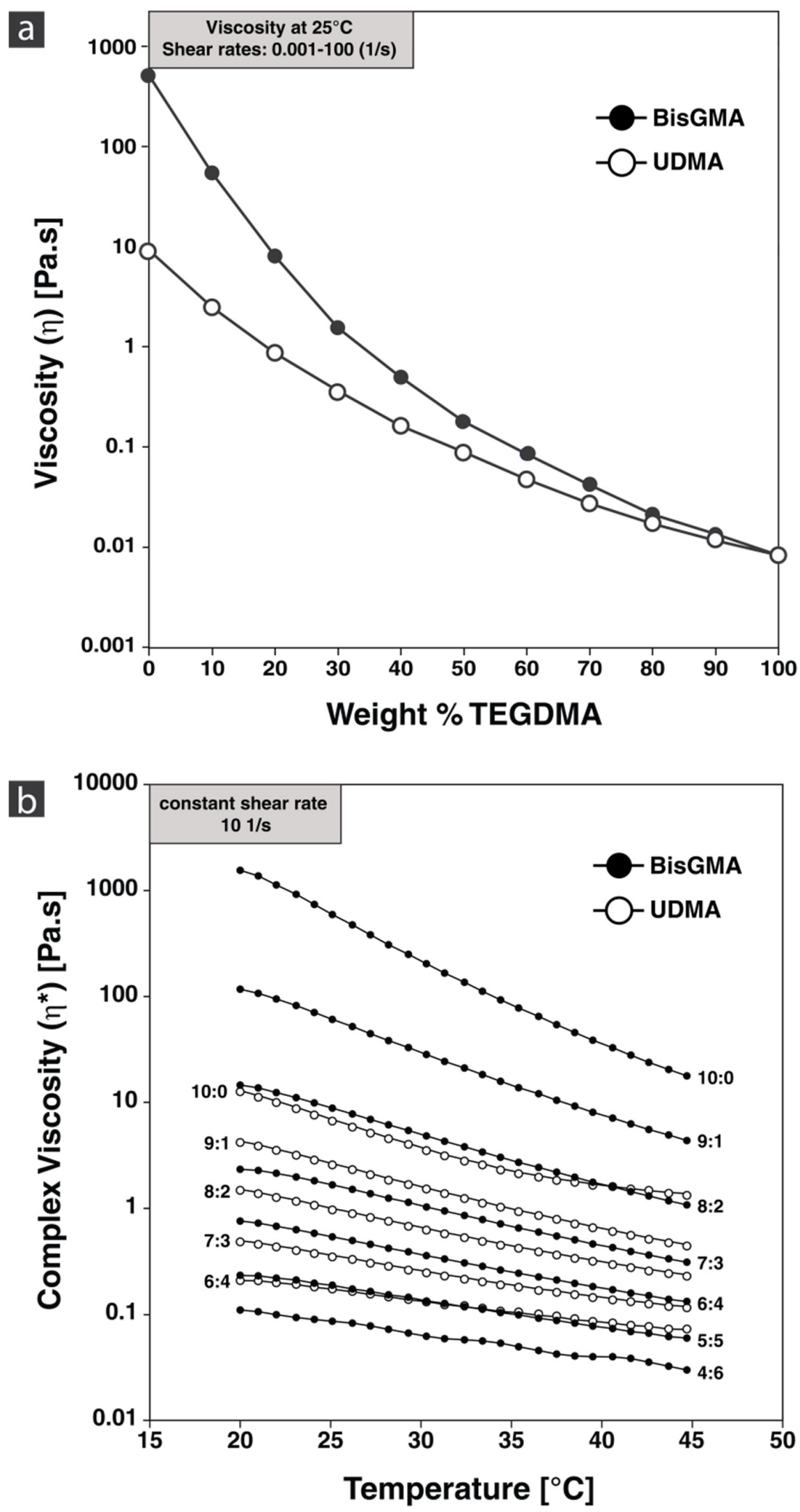

Figure 2. Viscosity of monomer formulations. (a) Shear sweep of monomer formulations at $25{ }^{\circ} \mathrm{C}$; (b) temperature sweep of monomer formulations. 
According to Darcy's law, the viscosity affects the fluid flow behavior into a porous substrate. Lower viscosity is needed for ease of flow, while a higher viscosity affects infiltration rate and pressure. One group [9] used pure UDMA for their PICN material, which at $10 \mathrm{~Pa} \cdot \mathrm{s}$, is several magnitudes greater than the 5:5 wt $\%$ BisGMA:TEGDMA (0.181 Pa.s), and UDMA:TEGDMA (0.090 Pa.s) commonly used by others. Monomer formulations greater than $10 \mathrm{~Pa} \cdot \mathrm{s}$ would be difficult for infiltration; therefore, with regard to viscosity, the formulations of BisGMA:TEGDMA 9:1 and 8:2 would fall out of this range. Viscosity is significantly influenced by changes in temperature; Figure $2 b$ shows complex viscosity with increasing temperature. Monomer formulations with viscosity less than $0.1 \mathrm{~Pa} \cdot \mathrm{s}$ were excluded from the temperature sweep. Temperature has such a pronounced effect on viscosity it is able to reduce viscosity by orders of magnitude. Therefore, most monomer formulations can reach low viscosities suitable for infiltration.

BisGMA in general shows higher viscosities compared to UDMA formulations, due to the differences in chain length of the used monomers. As consequence, the effect diminishes at higher TEGDMA ratios. A target viscosity for infiltration purposes should meet the criteria of sufficient flowability / penetrability into the network by retaining a minimum polymerization shrinkage and shrinkage stress at network interfaces. For BisGMA:TEGDMA, the optimum ratio is thus found between 7:3 and 5:5, while for UDMA:TEGDMA formulations, the window of applicability might be found between 9:1 and 6:4.

\subsection{Temperature Dependency}

Increasing temperature allows for many monomer formulations to reach a lower viscosity threshold for infiltration; however, there is a maximum limit placed on the temperature. Using free radical polymerization with the use of an initiator, Figure 3 shows temperature-dependent behavior of different monomer formulations. A greater difference between $G^{\prime \prime}$ and $G^{\prime}$ showing strong interaction forces is seen in formulations (2:8) and (5:5) for both UDMA:TEGDMA and BisGMA:TEGDMA, as opposed to formulations (8:2) for both UDMA:TEGDMA and BisGMA:TEGDMA, both showing a higher loss modulus $\left(G^{\prime \prime}\right)$ over storage modulus $\left(G^{\prime}\right)$ indicating weaker unlinked molecules. This hypothesis is based on observations in Figure 3, not accounting for differences in the chain structure of BisGMA versus UDMA with a higher concentration of crosslinking double bonds in UDMA. Sol/gel transition temperature $\mathrm{T}_{\mathrm{SG}}$ lies between 72.0 and $75.9^{\circ} \mathrm{C}$ for all formulations. All formulations with heat initiator $\mathrm{BPO}$ begin reactions around this temperature range. These values are in the range of temperatures selected for experimental PICN using BPO.
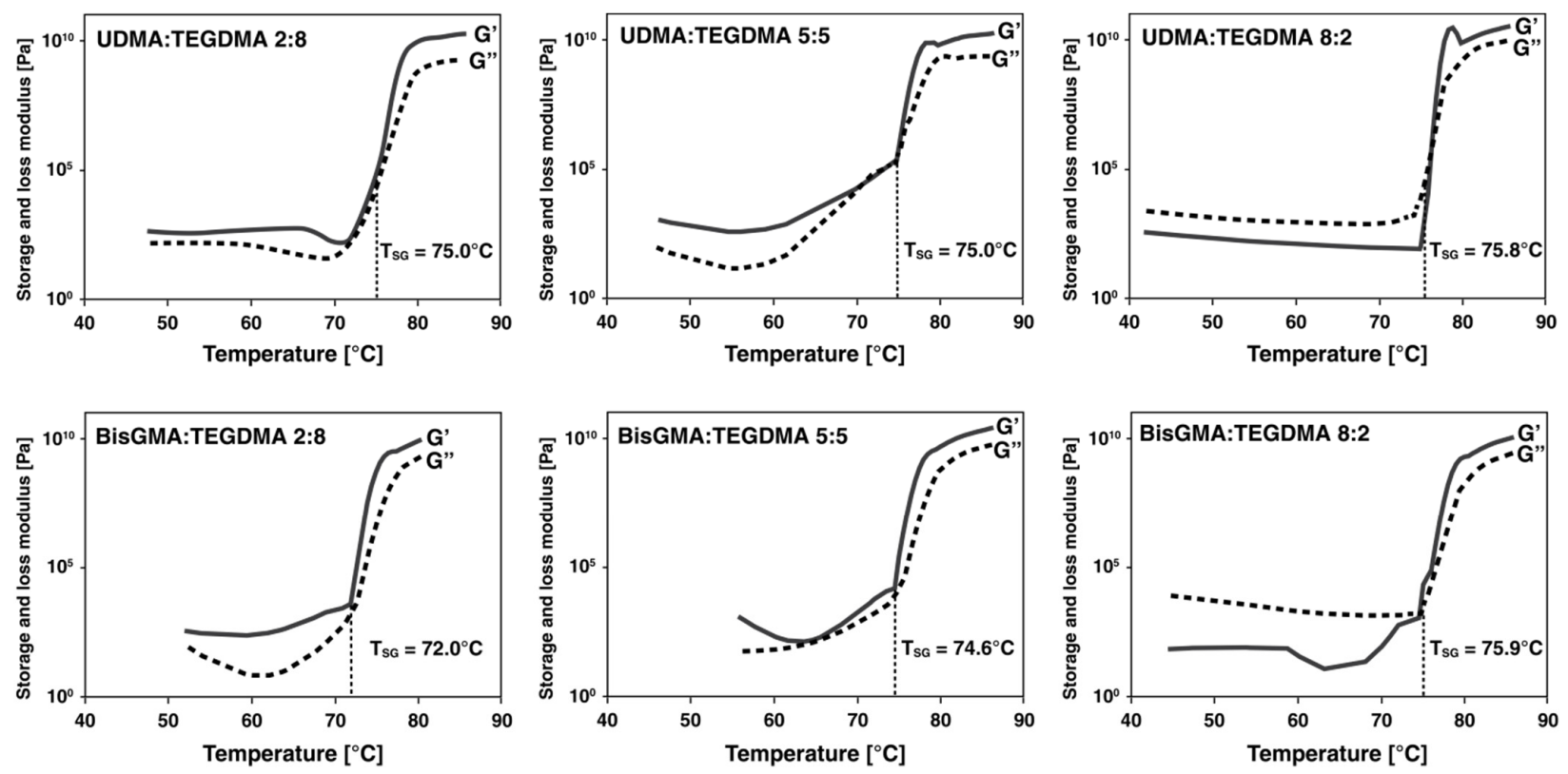

Figure 3. Temperature dependency of selected monomer formulations. 


\subsection{Degree of Conversion}

The degrees of conversion of the different monomer formulations cured at different temperatures using FTIR spectroscopy are shown in Figure 4. The conversion for BisGMA formulations ranged from 81.6 to $87.3 \%$. The UDMA formulations ranged from 74.2 to $86.4 \%$, with the exception being BisGMA:TEGDMA 2:8 and 1:9, which has significant amounts of TEGDMA (80-90 wt \%) with a conversion of $65.9 \%$ and $22.8 \%$, respectively. Pure TEGDMA is found to have low conversion [23]. The degree of conversion is analyzed in photo-polymerized resin as critically affecting mechanical properties. The BisGMA molecule has a stiff core, less degrees of freedom, and reduced mobility resulting in kinematically a low degree of conversion. Coupled with low viscosity TEGDMA, the network forms cross-links, which also reduces mobility as the reaction progresses. However, when the monomer formulations undergo heat-polymerization, there is no clear correlation with increasing TEGDMA seen in photo-polymerized monomer formulations. The difference is that heat-polymerization allows the continual required energy input to improve the mobility and reactivity. As a result, degree of conversion is independent of the amount of TEGDMA (as long as this is over $30 \mathrm{wt} \%$ when formulated with BisGMA). A study by Cui et al. showed comparable monomer conversion of $81.9 \%$ DC for BisGMA:TEGDMA (5:5) and $81.7 \%$ DC for UDMA:TEGDMA (8:2) mixtures [47]. This study used comparable experimental settings as they heat-polymerized with $1 \mathrm{wt} \% \mathrm{BPO}$ at $70{ }^{\circ} \mathrm{C}$ for $8 \mathrm{~h}$.
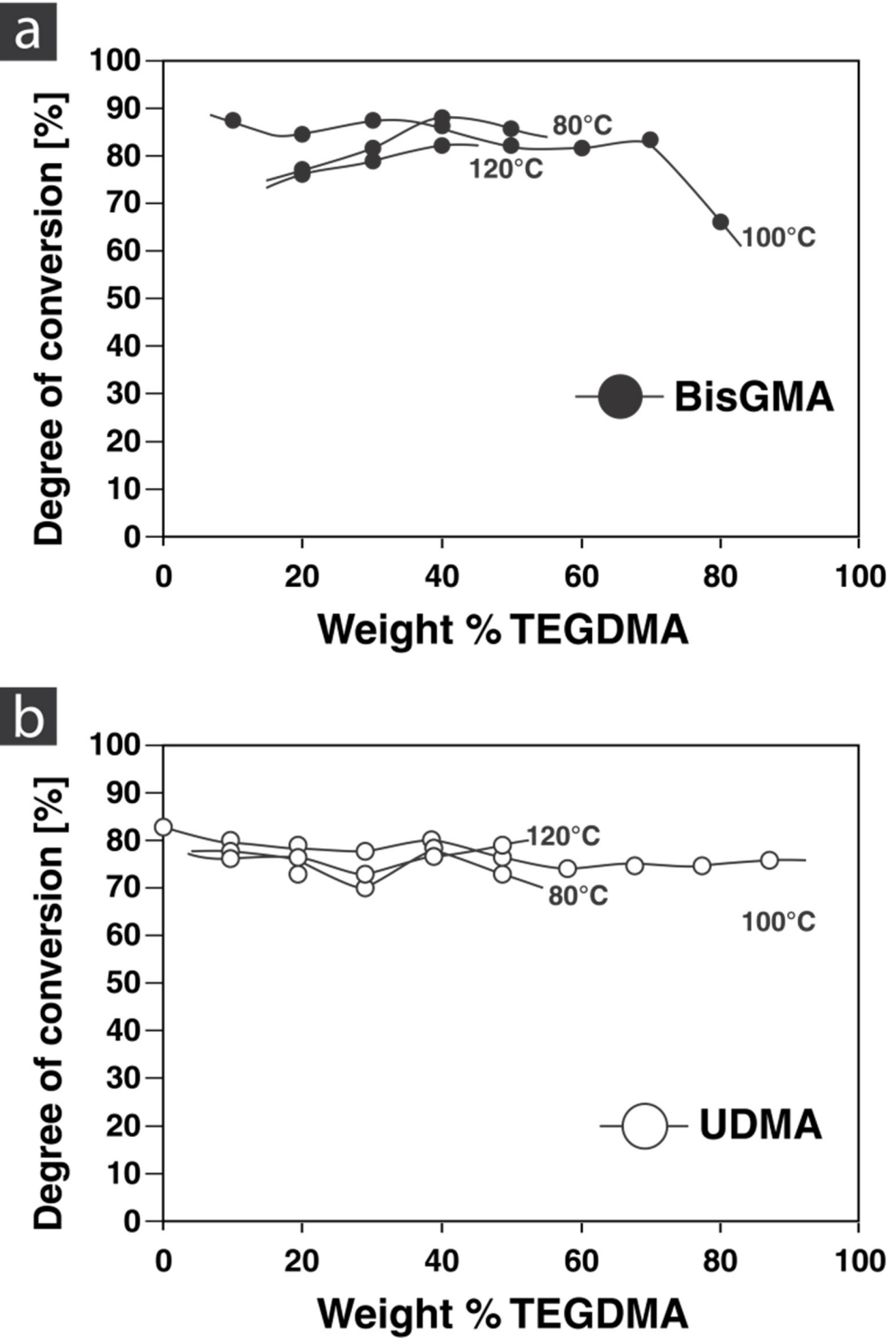

Figure 4. Degree of conversion of BisGMA:TEGDMA (a) and UDMA:TEGDMA (b) formulations. 


\subsection{Mechanical Properties}

Figure $5 \mathrm{a}, \mathrm{b}$ shows the elastic modulus and hardness of the monomer formulations cured at different temperatures and weight percentages of TEGDMA, respectively. There is a clear inverse correlation with the increase of TEGDMA in hardness, elastic modulus, and fracture toughness. The highest values for elastic modulus were seen in BisGMA:TEGDMA 8:2 (3.03 GPa) cured at $120^{\circ} \mathrm{C}$, and the lowest was UDMA:TEGDMA 1.9 (0.63 GPa) cured at $100{ }^{\circ} \mathrm{C}$. The temperature did not affect UDMA:TEGDMA formulations. The highest hardness values were seen in the BisGMA:TEGDMA 9:1 formulation $(249.07 \pm 8.47 \mathrm{MPa})$, and the lowest in UDMA:TEGDMA $1: 9(33.81 \pm 13.88 \mathrm{MPa})$. TEGDMA, with its low molecular weight, increases the flexibility of the polymer with an increase in weight ratio. This can be explained by the TEGMDA molecule's ability to coil under load and rotate about its ether linkages [37].

These properties are essential when considering dental restorations. Elastic properties and hardness should be as close as possible to the properties of our human teeth to replicate and establish the biomechanical functions and demands. A high hardness and elastic modulus can damage and abrade the opposing teeth, while the inverse would damage the restoration. Comparable damage tolerance is needed to absorb the loading energy and provide the essential durability and robustness for clinical success. In the case of high strength ceramics of alumina and zirconia, these strong and incredibly stiff ceramics can be made more compliant with the addition of monomers in PICN materials. Relative success in property matching has been seen in commercial dental PICN materials $[4,48]$.

Cui et al. used similar formulations for infiltration of silica-based ceramic networks [47]. They measured an elastic modulus for the final PICN material of $18.7 \mathrm{GPa}$ for BisGMA:TEGDMA (5:5) and 18.9 GPa for UDMA:TEGDMA (8:2) formulations, both values closely matching the dentin elasticity.

Figure $5 \mathrm{c}$ shows fracture toughness of the monomer formulations cured at different temperatures and weight percentages of TEGDMA. Basically, the fracture toughness was found considerably higher for UDMA- versus BisGMA-based formulations. Fracture toughness linearly decreased with increasing TEGDMA content. The highest values were seen in UDMA:TEGDMA formulations which ranged from $0.262 \pm 0.078 \mathrm{MPa} \cdot \mathrm{m}^{0.5}(1: 9)$ to $0.931 \pm 0.159 \mathrm{MPa} \cdot \mathrm{m}^{0.5}(9: 1)$. UDMA cured at $100{ }^{\circ} \mathrm{C}$ was $0.756 \pm 0.082 \mathrm{MPa} \cdot \mathrm{m}^{0.5}$, and BisGMA:TEGDMA formulations ranged from $0.179 \pm 0.043 \mathrm{MPa} \cdot \mathrm{m}^{0.5}(1: 9)$ to $0.683 \pm 0.113 \mathrm{MPa} \cdot \mathrm{m}^{0.5}$ (9:1). Fracture toughness is the ability of a material to resist crack growth from a pre-existing crack. In terms of clinical relevance, this mechanical property offers greater understanding of failure over elasticity. A resin formulation for infiltration purposes should hence exhibit a high fracture toughness with preference for UDMA-based mixtures at higher UDMA:TEGDMA ratios.

Clinical fractures often originate from existing flaws, and fracture toughness gives us a measure of the load needed to propagate the crack. The interpenetrating nature of PICN materials distinctly separates both material constituents; therefore, any advancing cracks are strongly subject to a variety of toughening mechanisms. When materials are effective in arresting developing cracks and absorb enough crack advancing forces, an increased input of energy is required to further propagate the crack, leading to a rising resistance curve (R-curve). Fracture toughness of a material is contributed to by intrinsic toughening mechanisms such as the inherent plasticity of the material working ahead of the crack tip [49]. As polymers are covalently bonded networks, at a critical shear strain, molecules are susceptible of sliding with respect to each other [50]. Having a low elastic modulus increases the amount of work done during flexure and in turn increases the strain energy release rate. These energy consuming processes inevitably increase the plastic zone around the crack tip leading to increased toughness. 
a

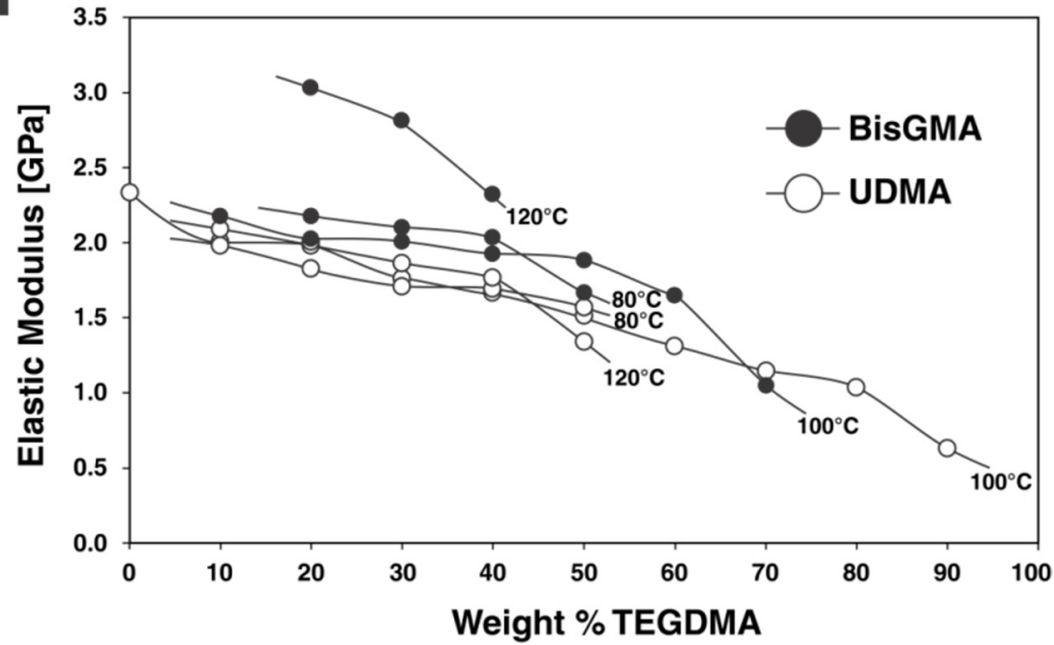

b

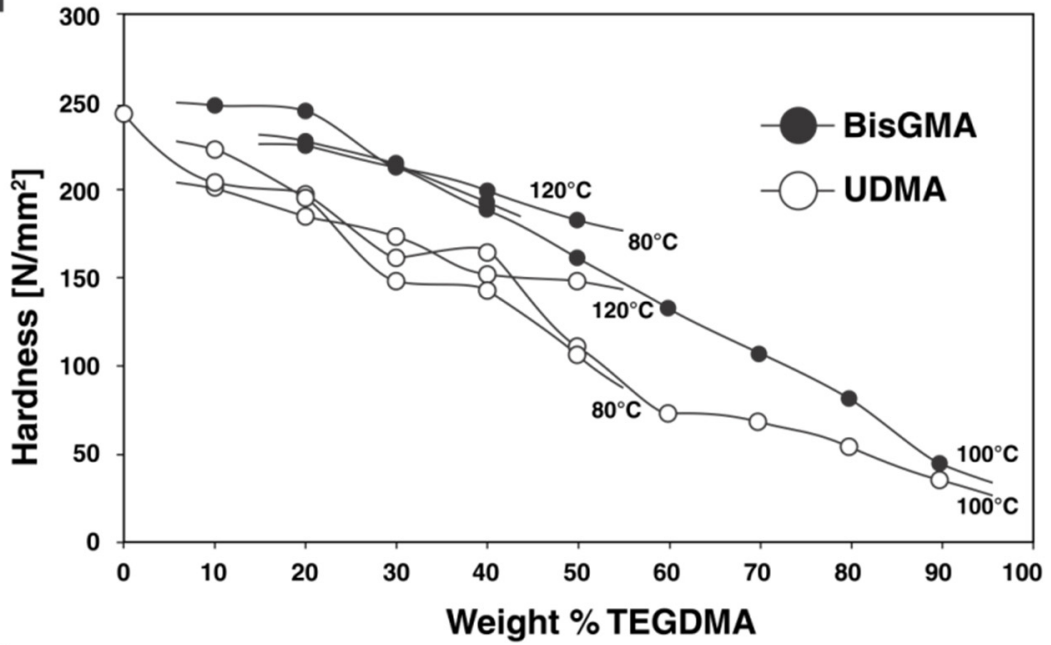

C

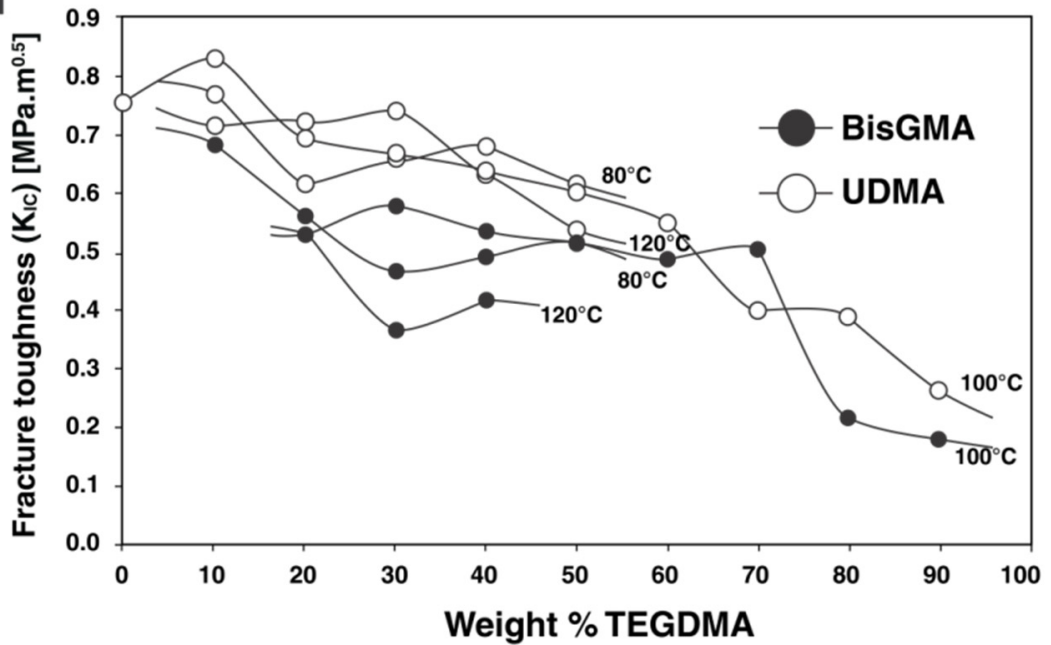

Figure 5. Mechanical properties of monomer formulations cured at different temperatures. Elastic modulus (a), hardness (b), and fracture toughness (c).

Conversely, extrinsic toughening mechanisms work outside of the inherent material property and inflict energy consuming processes working behind the crack tip such as crack bridging. The increasing R-curve is seen in interpenetrating networks of metals and ceramics where the metal acts as the compliant phase, and its ductility leads to bridging effects 
behind the crack tip [51]. Ceramics themselves are brittle in nature, meaning that at a certain load, cracks occur catastrophically. In the case of dental PICN materials, the monomer resin acts as the compliant phase and would be responsible for extrinsic toughening mechanisms if any were to exist. To our knowledge, significant rising R-curve behavior has not been seen in commercial dental PICN materials, but that is not to say that it is an impossible feat. With a slow enough loading rate, localized deformation leading to crazing will form in glassy polymers. With crack advancement, fibrils are left at the trailing edge [50]. Interpenetrating composites outside of dentistry using ceramic and polymers have indicated the potential of bridging polymer fibrils or ligaments using 6-Nylon infiltrated into porous hydroxyapatite leading to a rising R-curve [48,52]. Fibril bridging effects were also seen in calcium phosphate scaffolds with Poly (e-caprolactone) [53]. Going forward with experimental dental PICN materials, increasing the fracture toughness and inducing the favored R-curve effect in dental PICN materials require a proper understanding of the resin matrix and if the possibility of polymer fibrils exists.

It is difficult to compare the property differences between studies using dental monomer formulations. The composition and polymerization method can result in markedly different properties. However, based on information as outlined in Table 1, monomer compositions can be tailored to specific properties and applications. Selection of heatpolymerized monomer formulations must consider many variables. The infiltration of monomers relies on an appropriate viscosity; however, the temperamental response to temperature demonstrate that ideal viscosity can be achieved in most monomer formulations. With the addition of chemical initiator BPO, the monomer formulations need to achieve temperatures of at least $72.0-75.9^{\circ} \mathrm{C}$ to reach gelation and begin the reaction. By keeping the heating procedure as a constant variable, it was demonstrated that the degree of conversion is also unaffected by monomer formulations. These factors are important to consider with photo-polymerized composites but become inconsequential with heat-polymerized monomers. Instead, a pivotal consideration for resin matrix selection is assigned to the mechanical performance. It becomes clear how the relative concentration of monomers affects the contribution to mechanical performance. Increasing the TEGDMA ratio reduces elastic modulus, hardness, and fracture toughness. This could be due to the stronger hydrogen bonds in BisGMA and UDMA restricting the sliding of the molecules relative to each other over TEGDMA, with a pronounced effect due to concentration.

The importance for the selection of appropriate resin monomer formulations with specific chemical and physical properties is not just limited to infiltration purposes. The use of similar formulations with comparable relations between various properties has already been applied to 3D printing technologies. A study by Hodasova et al. has shown the performance of BisGMA:TEGDMA (4:6) formulations for infiltration of 3D-printed zirconia (3Y-TZP) networks [54]. Based on rapidly advancing additive manufacturing technologies, the importance of selecting appropriate resin formulations with specific properties for, e.g., simultaneous and multi-material printing techniques further increases.

\section{Conclusions}

Viscosity, temperature dependency, degree of conversion, and mechanical tests were performed on BisGMA:TEGDMA- versus UDMA:TEGDMA-based monomer formulations. The viscosity of UDMA was generally lower compared to BisGMA formulations, allowing for a higher UDMA:TEGDMA ratio. Both combinations heat-polymerized at $70{ }^{\circ} \mathrm{C}$ for $8 \mathrm{~h}$ using $1 \mathrm{wt} \%$ BPO proved a high degree of conversion of approximately $74-87 \%$ with a higher crosslinking density for BisGMA formulations. Elastic modulus and hardness were found slightly higher for BisGMA versus UDMA mixtures, linearly decreasing for both materials with increasing TEGDMA content. The fracture toughness as an ultimate measure of fracture resistance and hence reinforcing stability was considerably higher for UDMA versus BisGMA formulations, also linearly decreasing for higher TEGDMA mixtures. Taking into account the reduced viscosity of UDMA versus BisGMA thus allows for a higher UDMA:TEGDMA ratio, which is in turn beneficial for further expanding the window of applicability. 
Author Contributions: Conceptualization, J.T., R.B. and U.L.; methodology, J.T. and U.L.; software, J.T.; validation, R.B. and U.L.; formal analysis, J.T.; investigation, J.T.; resources, U.L.; data curation, J.T.; writing—original draft preparation, J.T.; writing—review and editing, U.L.; visualization, R.B.; supervision, U.L.; project administration, U.L.; funding acquisition, J.T. and U.L. All authors have read and agreed to the published version of the manuscript.

Funding: This research received external funding in the frame of a postdoctoral research fellowship from the Alexander-von-Humboldt Foundation for J.T.

Institutional Review Board Statement: Not applicable.

Informed Consent Statement: Not applicable.

Conflicts of Interest: The authors declare no conflict of interest.

\section{References}

1. Ferracane, J.L. Resin composite-State of the art. Dent. Mater. 2011, 27, 29-38. [CrossRef]

2. Cramer, N.; Stansbury, J.; Bowman, C. Recent Advances and Developments in Composite Dental Restorative Materials. J. Dent. Res. 2010, 90, 402-416. [CrossRef]

3. Al-Jawoosh, S.; Ireland, A.; Su, B. Fabrication and characterisation of a novel biomimetic anisotropic ceramic/polymer-infiltrated composite material. Dent. Mater. 2018, 34, 994-1002. [CrossRef]

4. Coldea, A.; Swain, M.; Thiel, N. Mechanical properties of polymer-infiltrated-ceramic-network materials. Dent. Mater. 2013, 29, 419-426. [CrossRef]

5. Cui, B.; Li, J.; Wang, H.; Lin, Y.; Shen, Y.; Li, M.; Deng, X.; Nan, C. Mechanical properties of polymer-infiltrated-ceramic (sodium aluminum silicate) composites for dental restoration. J. Dent. 2017, 62, 91-97. [CrossRef] [PubMed]

6. Cui, B.; Zhang, R.; Sun, F.; Ding, Q.; Lin, Y.; Zhang, L.; Nan, C. Mechanical and biocompatible properties of polymer-infiltratedceramic-network materials for dental restoration. J. Adv. Ceram. 2020, 9, 123-128. [CrossRef]

7. Cui, B.C.; Li, J.; Wang, H.N.; Lin, Y.H.; Shen, Y.; Nan, C.W. Mechanical Properties of Polymer-Infiltrated-Feldspar for Restorative Composite CAD/CAM Blocks. Key Eng. Mater. 2016, 697, 648-651. [CrossRef]

8. Cui, B.-C.; Li, J.; Lin, Y.-H.; Shen, Y.; Li, M.; Deng, X.-L.; Nan, C.-W. Polymer-infiltrated layered silicates for dental restorative materials. Rare Met. 2019, 38, 1003-1014. [CrossRef]

9. Eldafrawy, M.; Nguyen, J.; Mainjot, A.; Sadoun, M. A Functionally Graded PICN Material for Biomimetic CAD-CAM Blocks. J. Dent. Res. 2018, 97, 1324-1330. [CrossRef]

10. Li, J.; Zhang, X.-H.; Cui, B.-C.; Lin, Y.-H.; Deng, X.-L.; Li, M.; Nan, C.-W. Mechanical performance of polymer-infiltrated zirconia ceramics. J. Dent. 2017, 58, 60-66. [CrossRef] [PubMed]

11. Li, S.; Zhao, Y.; Zhang, J.-F.; Xie, C.; Zhao, X. Machinability of poly(methyl methacrylate) infiltrated zirconia hybrid composites. Mater. Lett. 2014, 131, 347-349. [CrossRef]

12. Li, S.B.; Zhao, Y.M.; Zhang, J.F.; Xie, C.; Li, D.M.; Tang, L.H.; Zhao, X.Y. Mechanical properties and microstructure of PMMA-ZrO2 nanocomposites for dental CAD/CAM. Adv. Mater. Res. 2013, 785, 533-536. [CrossRef]

13. Nguyen, J.; Ruse, N.D.; Phan, A.; Sadoun, M. High-temperature-pressure Polymerized Resin-infiltrated Ceramic Networks. J. Dent. Res. 2014, 93, 62-67. [CrossRef] [PubMed]

14. Petrini, M.; Ferrante, M.; Su, B. Fabrication and characterization of biomimetic ceramic/polymer composite materials for dental restoration. Dent. Mater. 2013, 29, 375-381. [CrossRef]

15. Steier, V.F.; Koplin, C.; Kailer, A. Influence of pressure-assisted polymerization on the microstructure and strength of polymerinfiltrated ceramics. J. Mater. Sci. 2013, 48, 3239-3247. [CrossRef]

16. Wang, F.; Guo, J.; Li, K.; Sun, J.; Zeng, Y.; Ning, C. High strength polymer/silicon nitride composites for dental restorations. Dent. Mater. 2019, 35, 1254-1263. [CrossRef] [PubMed]

17. Wang, H.; Cui, B.; Li, J.; Li, S.; Lin, Y.; Liu, D.; Li, M. Mechanical properties and biocompatibility of polymer infiltrated sodium aluminum silicate restorative composites. J. Adv. Ceram. 2017, 6, 73-79. [CrossRef]

18. Swain, M.; Coldea, A.; Bilkhair, A.; Guess, P. Interpenetrating network ceramic-resin composite dental restorative materials. Dent. Mater. 2016, 32, 34-42. [CrossRef]

19. Ruse, N.; Sadoun, M. Resin-composite Blocks for Dental CAD/CAM Applications. J. Dent. Res. 2014, 93, 1232-1234. [CrossRef]

20. Whitaker, S. Flow in porous media I: A theoretical derivation of Darcy's law. Transp. Porous Media 1986, 1, 3-25. [CrossRef]

21. Peutzfeldt, A. Resin composites in dentistry: The monomer systems. Eur. J. Oral Sci. 1997, 105, 97-116. [CrossRef]

22. Venhoven, B. De Gee, A.; Davidson, C. Polymerization contraction and conversion of light-curing BisGMA-based methacrylate resins. Biomaterials 1993, 14, 871-875. [CrossRef]

23. Floyd, C.J.; Dickens, S.H. Network structure of Bis-GMA- and UDMA-based resin systems. Dent. Mater. 2006, 22, 1143-1149. [CrossRef]

24. Stansbury, J.W.; Dickens, S.H. Network formation and compositional drift during photo-initiated copolymerization of dimethacrylate monomers. Polymer 2001, 42, 6363-6369. [CrossRef]

25. Dickens, S.H.; Stansbury, J.; Choi, K.; Floyd, C. Photopolymerization kinetics of methacrylate dental resins. Macromolecules 2003, 36, 6043-6053. [CrossRef] 
26. Lovell, L.G.; Berchtold, K.A.; Elliott, J.E.; Lu, H.; Bowman, C.N. Understanding the kinetics and network formation of dimethacrylate dental resins. Polym. Adv. Technol. 2001, 12, 335-345. [CrossRef]

27. Van Landuyt, K.L.; Nawrot, T.; Geebelen, B.; De Munck, J.; Snauwaert, J.; Yoshihara, K.; Scheers, H.; Godderis, L.; Hoet, P.; Van Meerbeek, B.; et al. How much do resin-based dental materials release? A meta-analytical approach. Dent. Mater. 2011, 27, 723-747. [CrossRef]

28. Mohsen, N.; Craig, R.G.; Hanks, C. Cytotoxicity of urethane dimethacrylate composites before and after aging and leaching. J. Biomed. Mater. Res. 1998, 39, 252-260. [CrossRef]

29. Rathbun, M.A.; Craig, R.G.; Hanks, C.T.; Filisko, F.E. Cytotoxicity of a BIS-GMA dental composite before and after leaching in organic solvents. J. Biomed. Mater. Res. 1991, 25, 443-457. [CrossRef]

30. Tanaka, K.; Taira, M.; Shintani, H.; Wakasa, K.; Yamaki, M. Residual monomers (TEGDMA and Bis-GMA) of a set visible-lightcured dental composite resin when immersed in water. J. Oral Rehabilitation 1991, 18, 353-362. [CrossRef] [PubMed]

31. Söderholm, K.-J.; Mariotti, A. BIS-GMA-based resins in dentistry: Are they safe? J. Am. Dent. Assoc. 1999, 130, 201-209. [CrossRef] [PubMed]

32. Schroeder, W.; Vallo, C. Effect of different photoinitiator systems on conversion profiles of a model unfilled light-cured resin. Dent. Mater. 2007, 23, 1313-1321. [CrossRef] [PubMed]

33. Sideridou, I.; Tserki, V.; Papanastasiou, G. Effect of chemical structure on degree of conversion in light-cured dimethacrylate-based dental resins. Biomaterials 2002, 23, 1819-1829. [CrossRef]

34. Furuse, A.Y.; Mondelli, J.; Watts, D. Network structures of Bis-GMA/TEGDMA resins differ in DC, shrinkage-strain, hardness and optical properties as a function of reducing agent. Dent. Mater. 2011, 27, 497-506. [CrossRef] [PubMed]

35. Asmussen, E.; Peutzfeldt, A. Influence of UEDMA, BisGMA and TEGDMA on selected mechanical properties of experimental resin composites. Dent. Mater. 1998, 14, 51-56. [CrossRef]

36. Barszczewska-Rybarek, I.M. Structure-property relationships in dimethacrylate networks based on Bis-GMA, UDMA and TEGDMA. Dent. Mater. 2009, 25, 1082-1089. [CrossRef]

37. Beatty, M.; Swartz, M.L.; Moore, B.K.; Phillips, R.W.; Roberts, T.A. Effect of crosslinking agent content, monomer functionality, and repeat unit chemistry on properties of unfilled resins. J. Biomed. Mater. Res. 1993, 27, 403-413. [CrossRef]

38. Pfeifer, C.S.; Silva, L.R.; Kawano, Y.; Braga, R.R. Bis-GMA co-polymerizations: Influence on conversion, flexural properties, fracture toughness and susceptibility to ethanol degradation of experimental composites. Dent. Mater. 2009, 25, $1136-1141$. [CrossRef]

39. Phan, A.C.; Tang, M.-L.; Nguyen, J.-F.; Ruse, N.D.; Sadoun, M. High-temperature high-pressure polymerized urethane dimethacrylate-Mechanical properties and monomer release. Dent. Mater. 2014, 30, 350-356. [CrossRef] [PubMed]

40. Li, W.; Sun, J. Effects of Ceramic Density and Sintering Temperature on the Mechanical Properties of a Novel Polymer-Infiltrated Ceramic-Network Zirconia Dental Restorative (Filling) Material. Med Sci. Monit. 2018, 24, 3068-3076. [CrossRef] [PubMed]

41. Guerra, R.M.; Duran, I.; Ortiz, P. FTIR monomer conversion analysis of UDMA-based dental resins. J. Oral Rehabil. 2008, 23, 632-637. [CrossRef] [PubMed]

42. Charton, C.; Falk, V.; Marchal, P.; Pla, F.; Colon, P. Influence of Tg, viscosity and chemical structure of monomers on shrinkage stress in light-cured dimethacrylate-based dental resins. Dent. Mater. 2007, 23, 1447-1459. [CrossRef]

43. Lemon, M.T.; Jones, M.S.; Stansbury, J.W. Hydrogen bonding interactions in methacrylate monomers and polymers. J. Biomed. Mater. Res. 2007, 83, 734-746. [CrossRef]

44. Moszner, N.; Salz, U. New developments of polymeric dental composites. Prog. Polym. Sci. 2001, 26, 535-576. [CrossRef]

45. Lee, J.-H.; Um, C.-M.; Lee, I.-B. Rheological properties of resin composites according to variations in monomer and filler composition. Dent. Mater. 2006, 22, 515-526. [CrossRef] [PubMed]

46. Beun, S.; Bailly, C.; Dabin, A.; Vreven, J.; Devaux, J.; Leloup, G. Rheological properties of experimental Bis-GMA/TEGDMA flowable resin composites with various macrofiller/microfiller ratio. Dent. Mater. 2009, 25, 198-205. [CrossRef] [PubMed]

47. Cui, B.; Sun, F.; Ding, Q.; Wang, H.; Lin, Y.; Shen, Y.; Li, M.; Deng, X.; Zhang, L.; Nan, C. Preparation and Characterization of Sodium Aluminum Silicate-Polymer Composites and Effects of Surface Roughness and Scratch Directions on Their Flexural Strengths. Front. Mater. 2021, 8, 655156. [CrossRef]

48. Nakahira, A.; Tamai, M.; Miki, S.; Pezzotti, G. Fracture behavior and biocompatibility evaluation of nylon-infiltrated porous hydroxyapatite. J. Mater. Sci. 2002, 37, 4425-4430. [CrossRef]

49. Ritchie, R.O. The conflicts between strength and toughness. Nat. Mater. 2011, 10, 817-822. [CrossRef]

50. Launey, M.E.; Ritchie, R.O. On the Fracture Toughness of Advanced Materials. Adv. Mater. 2009, 21, 2103-2110. [CrossRef]

51. Prielipp, H.; Knechtel, M.; Claussen, N.; Streiffer, S.; Müllejans, H.; Rühle, M.; Rödel, J. Strength and fracture toughness of aluminum/alumina composites with interpenetrating networks. Mater. Sci. Eng. A 1995, 197, 19-30. [CrossRef]

52. Pezzotti, G.; Asmus, S. Fracture behavior of hydroxyapatite/polymer interpenetrating network composites prepared by in situ polymerization process. Mater. Sci. Eng. A 2001, 316, 231-237. [CrossRef]

53. Peroglio, M.; Gremillard, L.; Gauthier, C.; Chazeau, L.; Verrier, S.; Alini, M.; Chevalier, J. Mechanical properties and cytocompatibility of poly( $\varepsilon$-caprolactone)-infiltrated biphasic calcium phosphate scaffolds with bimodal pore distribution. Acta Biomater. 2010, 6, 4369-4379. [CrossRef] [PubMed]

54. Hodásová, L.; Sans, J.; Molina, B.G.; Alemán, C.; Llanes, L.; Fargas, G.; Armelin, E. Polymer infiltrated ceramic networks with biocompatible adhesive and 3D-printed highly porous scaffolds. Addit. Manuf. 2021, 39, 101850. 